\section{Análise das equipes de referência em saúde mental: uma perspectiva de gestão da clínica}

\author{
Analysis of patient referral teams in mental health: \\ a clinical management perspective
}

\begin{abstract}
The study used a qualitative, evaluative, and participant methodology based on Gadamer's hermeneutics and the constructivist paradigm. The aim was to analyze the arrangement called "patient care teams" for treatment of psychotic patients in the context of Community Mental Health Services (CMHS). Data were collected in two cycles of 18 focus groups including health professionals, users, and family members at six CMHS III, including eight in-depth interviews with users of these services and two workshops aimed at developing a guide to evaluate CMHS practices. The arrangement's functions were described, emphasizing that the referral teams serve as clinical management levels, fostering followup of patients' unique needs in the field, through interdisciplinary work. This requires sustaining an ethical stance based on respect for otherness and clinical case work-up.
\end{abstract}

Patient Care Team; Mental Health Services; Clinical Governance
Lilian Miranda 1

Rosana T. Onocko-Campos 1

As políticas públicas brasileiras estão estruturadas a favor do avanço da Reforma Psiquiátrica e da configuração de redes de atenção que garantam o acesso qualificado. Nesse contexto, propõe-se que os Centros de Atenção Psicossocial (CAPS) sejam responsáveis pela organização da rede de Saúde Mental, posicionando-se como uma referência para os demais serviços nas questões que envolvem sofrimento mental 1 . Tal posicionamento exige que esses serviços respondam a dois mandatos: cumprir com sua função de saúde pública, respondendo na cultura pelo endereçamento da loucura, e fazê-lo segundo uma clínica sustentada no acolhimento e no acompanhamento singular da construção subjetiva feita por cada paciente ${ }^{2}$.

A complexidade que envolve o trabalho proposto aos CAPS exige a criação de arranjos que facilitem a aproximação singularizada entre profissionais, pacientes e território de vida destes, possibilitando a construção e o acompanhamento de projetos terapêuticos sensíveis às necessidades peculiares a cada sujeito na relação consigo, com o seu sofrimento, com o CAPS e com o meio social que habita ${ }^{3}$. Um dos arranjos destinados a tal finalidade é o trabalho de referência, organizado através de profissionais ou equipes de referência ${ }^{4}$. Seu funcionamento baseia-se na formação de vínculo entre usuários e profissionais e na co-construção do 
tratamento 5, de tal modo que, mediante a elaboração compartilhada do projeto terapêutico, um profissional ou um grupo deles toma para si os encargos do acompanhamento do paciente em suas diferentes facetas, tais como questões emocionais, familiares, educacionais, habitacionais, laborais e financeiras 6 .

Material elaborado pelo Ministério da Saúde explicita que cabe ao terapeuta de referência, em contínuo diálogo com sua equipe técnica e com o usuário, monitorar junto deste o seu projeto terapêutico individual, fazer contatos com a família do paciente e avaliar periodicamente as metas traçadas 1 . Recente trabalho avaliou $78,88 \%$ dos CAPS existentes no país e aponta que $49 \%$ destes trabalham a partir do técnico de referência e $31,8 \%$ utilizam o modelo de mini-equipes de profissionais de referência como dispositivos de acompanhamento dos projetos terapêuticos individualizados 7 .

A despeito da ampla utilização desse arranjo, bem como de sua importância para a viabilização do tratamento, ainda são escassos os trabalhos que avaliam sua implantação e funcionamento, bem como balizamentos éticos e conceituais que o sustentam 6,8 .

No contexto internacional, o arranjo cujas funções se aproximam daquelas delegadas às equipes de referência é o Case Management. Trata-se de um processo em que um profissional, ou uma equipe, toma para si a responsabilidade de sustentar um relacionamento de suporte com um paciente no seu ambiente, identificando e assegurando-lhe a gama de recursos internos e externos essenciais para a vida em sociedade. Evidenciou-se que contribui para diminuir drasticamente o número de internações psiquiátricas e aumentar a qualidade de vida dos pacientes 9 .

Nos Estados Unidos, as abordagens terapêuticas do Case Management dividem-se entre Brokering Case Management e Clinical Case Management. Para o primeiro, a equipe é responsável pela inserção do paciente no meio extra-hospitalar, favorecendo as adaptações necessárias. Já no segundo, os profissionais se colocam como terapeutas primários, realizando ações de gerenciamento e de terapêutica clínica. Uma das vantagens do arranjo é sua flexibilidade para com as necessidades dos usuários, adotando uma abordagem multidisciplinar e orientações terapêuticas que almejam a reinserção social do paciente e não apenas a remissão de sintomas 10 .

Nesse artigo apresentamos os resultados de uma pesquisa cuja pergunta central diz respeito ao modo como o trabalho das equipes de referência vem sendo efetuado na rede de CAPSIII de uma cidade brasileira de grande porte, segundo a perspectiva de profissionais desses serviços e de usuários e familiares nela assistidos. Interrogamo-nos acerca da dinâmica de trabalho que vem sendo desenvolvida pelas equipes de referência e da clínica. Nosso objetivo é construir uma reflexão acerca das potências e limites desse arranjo na organização do processo de trabalho e na prática clínica, quando envolve pacientes psicóticos, no contexto dos CAPS.

\section{Método}

Este trabalho utilizou uma metodologia qualitativa e participante, baseada na Hermenêutica Gadameriana 11,12 e no paradigma construtivista 13 Trata-se de um subprojeto da Pesquisa Avaliativa de uma Rede de Centros de Atenção Psicossocial: Entre a Saúde Coletiva e a Saúde Mental 14. Nesse subprojeto estudamos, especificamente, o trabalho desenvolvido pelas equipes de referência nos CAPSIII da cidade de Campinas, São Paulo, nos seus aspectos clínicos e organizacionais.

O paradigma construtivista baseia-se numa perspectiva relativista que considera que a verdade é construída por consensos, e a pesquisa é fruto de interações e reconstruções mútuas entre objeto, investigador e realidade estudada 13 . A metodologia hermenêutica envolve contínua e dialética análise, estruturada através de processos em que o pesquisador busca compreender os sentidos produzidos pelos sujeitos, priorizando aquilo que lhes é consensual, e indica uma unidade de sentido. Entende-se que os sujeitos são históricos e sua linguagem é limitada ao tempo e ao espaço em que foi construída, sendo necessário considerar o contexto de produção e as tradições que o sustentam. Esse contexto permanece como um "pano de fundo" durante toda a pesquisa, porque o objeto não é dele recortado, mas destacado 11,12 . Na pesquisa que vimos apresentando, o objeto de estudo é o trabalho das equipes de referência, destacado do contexto de uma rede de CAPSIII comprometida com o avanço da Reforma Psiquiátrica. Portanto, as equipes de referência são analisadas em sua interação com esses serviços e a rede que os contempla.

\section{Procedimentos utilizados na coleta de dados}

- Duas rodadas de seis grupos focais 15 , com cerca de 12 profissionais cada, de categorias diversas, agrupados por CAPSIII. Tratou-se de um grupo por cada CAPSIII da cidade.

- Duas rodadas de um grupo focal, composto por dois profissionais de cada CAPSIII da cidade.

- Duas rodadas de um grupo focal constituído por dois usuários de cada CAPSIII da cidade. 
- Duas rodadas de um grupo focal constituído por dois familiares de usuários de cada CAPSIII da cidade.

- Oito entrevistas em profundidade com, pelo menos, um usuário de cada CAPSIII da cidade.

- Duas rodadas de uma oficina de construção de parâmetros sobre o tema Projeto Terapêutico Individual e Trabalho de Referência 14.

\section{Seleção dos sujeitos de pesquisa}

Para a composição dos grupos focais, utilizamos amostra intencional. O critério de inclusão dos profissionais foi a inserção de mais de seis meses no serviço e o interesse em participar da pesquisa. Solicitamos o comparecimento de representantes das diferentes categorias de nível superior e médio que trabalhassem diretamente na assistência. $\mathrm{O}$ critério de homogeneidade foi o local de trabalho. Compareceram médicos, enfermeiros, terapeutas ocupacionais, psicólogos e técnicos de enfermagem.

Para o grupo focal que tratou especificamente do trabalho de referência, utilizamos os mesmos critérios. Embora tivéssemos convidado todas as categorias profissionais, apenas psicólogos e médicos se interessaram por participar. As equipes justificaram o desinteresse dos outros profissionais, assinalando que estes já tinham comprometido sua agenda com a participação dos grupos focais que aconteceram anteriormente.

O critério de escolha dos usuários tanto para os grupos, como para as entrevistas, foi o interesse em participar da pesquisa e a experiência de utilização do leito noite no CAPS. Especificamente para as entrevistas, também foi critério de inclusão o psicodiagnóstico de psicose, segundo a avaliação da própria equipe. O critério de inclusão dos familiares foi o interesse em participar da pesquisa.

As oficinas foram compostas por usuários, familiares, profissionais e gestores dos CAPS, bem como por representantes de unidades básicas de saúde (UBS) e Centro de Convivência, totalizando 30 participantes. Esses atores foram convidados pelos CAPS que participaram do estudo. $\mathrm{O}$ critério de seleção foi o desejo de participação.

Não houve perda de sujeitos entre as duas rodadas de grupos e oficinas. Todos assinaram o termo de consentimento livre-esclarecido, de acordo com a Declaração de Helsinki. A pesquisa foi aprovada pelo Comitê de Ética da Faculdade de Ciências Médicas da Universidade Estadual de Campinas (protocolo 396/2004) e pela Prefeitura Municipal de Campinas. Sua realização se deu entre 2006 e 2008 e contou com financiamento do Conselho Nacional de Desenvolvimento Científico e Tecnológico (CNPq; edital 07/2005) e da Coordenação de Aperfeiçoamento de Pessoal de Nível Superior (CAPES; bolsa de doutorado).

\section{Organização do trabalho de campo}

Todos os grupos focais de trabalhadores agrupados por CAPS foram conduzidos a partir de um mesmo roteiro de questões semidirigidas, com as seguintes temáticas: formas de atenção ao usuário em momentos de crise; projeto terapêutico individual e equipe de referência; práticas grupais; concepção de CAPS e articulação com a rede; formação educacional e sofrimento psíquico. Neste artigo, apresentamos as discussões que envolvem a temática "equipe de referência”. Esta foi tratada a partir de questões sobre o modo de organização das equipes de referência, a função dos profissionais de referência no tratamento dos pacientes, a forma de construção do projeto terapêutico, as atividades próprias do trabalho de referência, a clínica praticada a partir desse arranjo, a relação entre as equipes de referência e a organização do fluxo assistencial 14 .

O grupo composto por dois profissionais de cada CAPS teve o objetivo de aprofundar as questões que envolvem as equipes de referência, abordadas nos grupos focais anteriores. Sendo assim, retomamos apenas a parte do roteiro que trata dessa temática.

Os grupos compostos por usuários e familiares abordaram as temáticas: vivência da crise e uso do leito noite, experiências de internação, descrição do tratamento, relação com as equipes de referência, experiência de práticas grupais e de inserção em serviços fora do CAPS. No presente trabalho, apresentamos as discussões que envolvem a temática "relação com as equipes de referência”, tratada a partir de questões sobre o acompanhamento recebido dos profissionais de referência e a importância destes para o tratamento 14 .

Realizamos a transcrição literal de cada grupo focal da primeira rodada e, com base nesta, construímos uma narrativa 16 que representava a discussão, evidenciando polêmicas, consensos e dissensos. Na segunda rodada, apresentamos essa narrativa para os mesmos grupos, de modo que eles pudessem validá-la e aprofundar suas argumentações. Com essa apresentação, fizemos a primeira volta do círculo hermenêutico, na medida em que levamos para os sujeitos narrativas acerca de suas discussões, permitindo-lhes construir uma meta-análise 14.

Em seguida, trabalhamos o material construído em cada grupo focal, identificando os argumentos que apontavam dificuldades oriundas das práticas das equipes de referência, bem como aqueles que descreviam as vantagens 
desse arranjo e aqueles que divergiam sobre algumas das suas funções. Categorizamos esse conteúdo em "problemas", "controvérsias" e "soluções" e levamos o material para uma nova análise, efetuada em oficinas. Na primeira sessão de oficinas, os sujeitos elegeram quais aspectos necessitariam de monitoramento avaliativo. Na segunda, construíram parâmetros para o trabalho de referência. Note-se que as oficinas ampliaram a diversidade de sujeitos, possibilitando que a construção do monitoramento avaliativo fosse pactuada com outros atores da rede de saúde 14 .

A realização de dois ciclos de grupos focais, seguidos de dois ciclos de oficinas, permitiu-nos construir a análise do material junto dos sujeitos de pesquisa, num processo de contínua revisão dos argumentos. Assim, procuramos cumprir com o postulado hermenêutico de passar várias vezes pelo mesmo lugar, mas cada qual de "latitude diferente", ampliando as possibilidades de compreensão da realidade estudada 11 .

Propusemos aos sujeitos entrevistados um novo encontro, para a leitura de uma narrativa que construiríamos valendo-nos da entrevista. Entretanto, eles não se dispuseram a isso, justificando que não gostariam de ouvir novamente aquilo que haviam nos contado.

Para a análise final dos resultados, fizemos outra volta hermenêutica, propondo um diálogo entre as narrativas produzidas nos grupos, oficinas e entrevistas com as tradições teóricas do campo da saúde mental e da psicanálise. Para isso, identificamos os principais núcleos argumentais de cada uma dessas narrativas e os dividimos segundo as categorias: formas de organização do arranjo; funções e tarefas a ele associadas; clínica e organização da assistência.

A seguir apresentamos os resultados construídos através de todos os procedimentos citados. Ressalte-se que destacamos dos grupos focais apenas as discussões que versavam sobre o trabalho das equipes de referência. As oficinas e entrevistas já tinham essa temática como central.

\section{Resultados}

A cidade estudada possui 1.064.669 de habitantes e está dividida em cinco Distritos Sanitários, cada qual com, pelo menos, um CAPSIII. Ao todo, são 49 UBS, 27 das quais contam com profissionais de saúde mental. Há ainda um CAPSi, dois CAPSad, 38 serviços residenciais terapêuticos (gerenciados pelos CAPS III), três enfermarias psiquiátricas em hospitais gerais, Serviço de Urgência com psiquiatra, Núcleo de Oficinas de Trabalho e cinco Centros de Convivência. Ca- da CAPSIII é referência para o atendimento de saúde mental de seu Distrito Sanitário e realiza trabalho de apoio matricial nas UBS. Os pacientes procuram os CAPS por demanda espontânea ou por meio de encaminhamentos, podendo se vincular a outros serviços, conforme seu projeto terapêutico 17 .

\section{Formas de organização do arranjo}

Os CAPS analisados adotam o modelo de equipes de referência, organizando seu trabalho de diferentes formas. Três deles trabalham com trios de referência, compostos por um profissional universitário, não médico, e outros de nível médio. Cada três trios compõem uma equipe de referência, que "é acompanhada por um médico" e se configura como espaço de discussão dos casos. O acompanhamento dos pacientes é realizado pelos membros do trio.

Dois CAPS trabalham com o modelo de equipes de referência compostas por profissionais universitários de diferentes categorias e técnicos de enfermagem. Dentro dessas equipes, cada profissional universitário não médico é a referência mais próxima para determinado número de pacientes. O médico acompanha todos os pacientes da sua equipe, embora não seja referência específica de nenhum deles. Os técnicos de enfermagem participam ativamente do trabalho de referência, mas sempre acompanhando profissionais universitários. Nessas composições, há uma divisão de responsabilidades e tarefas, e os possíveis conflitos não foram explicitados pelos grupos. Assim, além de espaço de discussão de casos, a equipe se configura como organização privilegiada para o compartilhamento das diferentes funções que cada paciente requer.

Um dos CAPS trabalha com o modelo de equipes de referência, sem delegar profissionais de referência específicos para cada paciente. Todos os profissionais compartilham as atividades e responsabilidades que envolvem o tratamento dos usuários da sua equipe.

Essa diversidade na conformação do arranjo é reconhecida pelos profissionais dos diferentes CAPS. Entretanto, de forma geral, as principais funções, os problemas e as potencialidades atribuídos ao trabalho de referência coincidiram no discurso dos sujeitos de pesquisa dos vários serviços. Sendo assim, optamos por apresentar os resultados sem diferenciá-los segundo o tipo de organização do arranjo.

\section{Funções e tarefas associadas ao arranjo}

Os profissionais defendem que o modelo de equipe de referência é útil para viabilizar a discussão 
interdisciplinar dos casos e o compartilhamento das responsabilidades. Contribui para que os usuários formem laços afetivos com mais de um técnico e para que este evite sua própria cronicidade, uma vez que é questionado por outras concepções científicas e chamado a desenvolver práticas que ultrapassam seu núcleo profissional. Um profissional diz: “...tem que gostar de estar lá e disponível, porque (...) a gente lá é profissional de referência, vai muito além do meu núcleo; eu, como psicóloga, não era pra dar banho e eu dou banho...".

Em outro grupo, no entanto, embora admitam certa "polivalência", inerente ao referenciar, os profissionais asseveram que o campo de trabalho "não pode suportar qualquer mistura" e explicitam o incômodo com a indeterminação de papéis, para os quais "nem sempre tiveram uma formação específica”.

Os grupos não indicam atividades que sejam desenvolvidas prioritariamente por uma categoria ou outra, com exceção da prescrição médica. O trabalho de cada técnico parece ser mais direcionado pelas necessidades do paciente do que por seu núcleo de formação, o que é avaliado, concomitantemente, como um fator de potência e angústia. Ainda que não tenhamos feito uma categorização de resultados pautada pela diferenciação de categorias profissionais, pudemos identificar que os técnicos de enfermagem foram aqueles que mais mostraram preocupação com a falta de formação para atividades que exigem contato afetivo intenso com os pacientes.

\section{Clínica e organização do serviço}

Os profissionais designam o técnico de referência como o "pivô", o "chave", o "coração" do CAPS. Explicam que ele tem a função de articulação do tratamento junto ao paciente, identificando as necessidades, desejos, limites e possibilidades deste, em diversos âmbitos. Reconhecem que é esperado que a equipe de referência facilite a circulação do paciente entre os diversos profissionais, contudo sempre há um ou dois deles de quem cada usuário é mais próximo.

Ao discutir as diferentes configurações do arranjo, os profissionais concluem que é a "direção clínica" que deve determinar se o trabalho se estrutura a partir do modelo de um ou dois profissionais de referência centrais, ou a partir da equipe, com as funções diluídas. Portanto, entendem que as diversas configurações possuem vantagens, conforme as necessidades de cada paciente. Porém, contam que há grande dificuldade em formar redes dentro e fora do CAPS, ainda que se trabalhe em equipe de referência. Afirmam que é comum que o profissional de referência seja “...responsabilizado pela vida do paciente e não apenas pelo seu tratamento...”, ou que “...a equipe deposite nele tudo que é difícil para ela lidar coletivamente...”. Nessas situações, bastante frequentes, é como se dissessem uns aos outros "toma que o filho é seu", o que lhes representa risco de praticar formas de controle sobre o usuário.

A constituição de redes externas ao CAPS é reconhecida como essencial, mas de difícil sustentação, devido à escassez de recursos comunitários e à sobrecarga do trabalho (associada, principalmente, ao grande número de pacientes). Vários profissionais fazem apoio matricial nas unidades básicas e despendem esforços para o compartilhamento de ações junto a serviços do território dos pacientes. Entretanto, avaliam que essas iniciativas são insuficientes e entendem que as UBS também se encontram sobrecarregadas, tendo pouco tempo para a construção de um trabalho compartilhado com o CAPS e apresentando dificuldades em destinar a atenção devida aos pacientes de saúde mental.

Segundo esses sujeitos, a natureza e a diversidade de funções que envolvem o trabalho dos profissionais de referência constituem outro aspecto que dificulta a sustentação da clínica. Dentre essas funções, encontram-se as denominadas de "burocráticas", tais como preenchimento de APACs (Autorização de Procedimentos de Alta Complexidade) e formulários para aquisição de benefícios, e aquelas ligadas à sobrevivência dos usuários, como aquisição de documentos pessoais, alimentação e moradia.

Quando não discutidas e compartilhadas, essas práticas acarretam sobrecarga de trabalho e sofrimento. Segundo os profissionais, “...a equipe ou o profissional de referência vão responder pelo tratamento do ponto de vista prático, vão gerenciar mesmo. (...) Mas, cada profissional escolhe se prefere responsabilizar-se apenas pelas questões práticas, sendo puramente burocrático, ou se pretende oferecer um contorno clínico para suas condutas...".

Para os familiares, a disponibilidade dos profissionais e o acompanhamento de necessidades cotidianas e situações de crise são os fatores que definem o trabalho das equipes de referência. Eles percebem que os técnicos de referência são aqueles mais próximos do paciente e valorizam a possibilidade de serem atendidos, sempre que necessário, por profissionais com quem estão vinculados. Destacam a importância de contarem com assistência às necessidades cotidianas, como preenchimento de formulários e, em sua maioria, dizem frequentar o CAPS principalmente nos momentos de crise do usuário. Nessas situações, é com o profissional de referência que 
conversam sobre os problemas que estão vivenciando e as providências necessárias.

Os usuários pouco falam das equipes de referência (constituída pelos profissionais), mas discorrem enfaticamente acerca de uma atividade terapêutica grupal, denominada "grupo de referência”. Trata-se de um espaço formal, de encontros semanais, entre parte dos profissionais e dos usuários de uma mesma equipe de referência. Dizem que é nesse grupo que "ficam sabendo como está a vida do outro", pois compartilham experiências.

Identificam um ou dois profissionais como os "seus referências" e reportam-se a outros como “da sua referência”, aludindo à equipe de referência. Explicam que o profissional de referência é pessoa com quem conversam e tomam decisões. Foi quem os recebeu no CAPS, percebe quando não estão bem ou não vão ao serviço, faz visitas em casa, conversa com a família, indica leito noite, visita-lhes nas internações hospitalares, ajuda a conseguir benefícios, procurar trabalho e lugar para viver.

A realização de tantas funções parece ser facilitada pela organização em equipe de referência, já que esta permite que os profissionais se alternem de modo que um deles sempre esteja no serviço. Uma paciente pontua: "Eu diria que o grupo [equipe] de referência é um determinado número de pessoas que cuidam da gente. Se um funcionário tira férias, ou se ausenta, há outra pessoa com quem você pode contar...". Para que as equipes de referência funcionem dessa forma, identificamos dois fatores fundamentais: a constância do acompanhamento e a disponibilidade dos profissionais em acompanhar os pacientes nas diversas questões que lhes são necessárias. Assim, a mesma usuária continua: “...A relação que eu tenho com as psicólogas da minha referência é diferente daquela que tenho com outros profissionais do CAPS. Os outros não me conhecem; se eu vou conversar com eles, preciso contar toda a minha história novamente. E, para mim, isso não dá certo".

Através desse acompanhamento constante, outro fator valorizado pelos usuários é a possibilidade de serem percebidos singularmente, ainda que nem sempre consigam expressar aquilo que estão sentindo. Uma paciente pondera: “...uma referência que conhece a paciente, por conversar com ela há muito tempo, poderá perceber que alguma coisa está errada, como um pensamento de suicídio...". Já outra paciente assevera que, para ter tal percepção, a profissional de referência “... precisa acreditar nas verdades do paciente. Não pode ir dando sentença...".

Todos os pacientes evidenciam ter relações de intensa proximidade e confiança com seus profissionais de referência, com quem contam para diversos tipos de mediação da vida cotidiana. Todavia, tal proximidade apresenta alguns riscos de práticas controladoras. Uma paciente conta: "Referência é uma pessoa que toma conta da gente. Ela toma conta de mim, ela é minha responsável, é ela que comanda tudo direitinho o que eu tenho que fazer, é ela que arrumou o benefício para mim, que fica com o dinheiro, que controla tudo".

\section{Por um monitoramento avaliativo}

A realização das oficinas permitiu que os sujeitos analisassem esses resultados e construíssem alguns parâmetros para a avaliação contínua daqueles aspectos eleitos como problemáticos. Assim, propuseram formas de acompanhar o trabalho de referência no cotidiano dos serviços, pautadas nas seguintes questões:

- Qual a porcentagem de pacientes que tiveram seu caso discutido no último ano?

- Quantas dessas discussões incluíram o paciente e sua família?

- A equipe de referência discute, pelo menos, dois casos por semana?

- Os pacientes são atendidos, em grupo ou individualmente, por outros profissionais além do seu profissional de referência e do seu médico?

\section{Discussão}

Sabemos que a organização de uma equipe não garante a comunicação efetiva entre seus componentes nem, tampouco, a aproximação destes com os usuários. Os profissionais parecem pontuar essa problemática quando dizem sentirse excessivamente responsabilizados pelo caso, embora trabalhem em equipe de referência e reconheçam situações de compartilhamento. Nesse sentido, alguns autores sugerem que o funcionamento das equipes requer permanente construção de pontes que permitam o tráfego entre os profissionais, de tal modo que coloquem afinidades e diferenças em contato, sem negálas ou emudecê-las 6. Quando desobstruído, esse tráfego permite que os pacientes circulem pelo serviço e pelos trabalhadores, encontrando distintos espaços de expressão e acolhimento para as suas experiências 18 .

Indicamos que o sustentáculo principal dessas pontes seja a construção do caso clínico, a qual permite que o paciente delineie os caminhos que permeiam seu tratamento e indique suas necessidades, ao seu modo ${ }^{18}$, tal como uma usuária recomenda ao afirmar que o profissional de referência "precisa acreditar nas verdades 
do paciente". Esse trabalho exige um saber-fazer pautado nas relações cotidianas que envolvem a vida do paciente e, por isso, não pode ser completamente governado por planos pré-definidos. É necessário que o profissional suspenda seus saberes e tenha paciência e perseverança para acompanhar os passos do usuário no seu mundo social, ajudando-o a ampliar suas possibilidades de relação, no ritmo que lhe é possível 19.

Instiga-nos identificar que profissionais e usuários localizam a clínica em lugares distintos: enquanto estes sentem-se cuidados quando recebem ajuda para a mediação da vida cotidiana, aqueles questionam-se acerca de tais práticas, entendendo que elas requerem um "contorno" clínico, e incomodam-se com a possibilidade de que se transformem em assistencialismo. Tal incômodo é anunciado tanto pelos técnicos universitários, quanto por aqueles de nível médio, que explicitam a sensação de que o campo não pode admitir tanta mistura.

Alguns autores nos ajudam a lidar com esse contraste, defendendo que o trabalho clínico do profissional de saúde mental é político e se faz a partir das relações cotidianas do paciente, devendo instigá-lo a aumentar sua autonomia, favorecendo, concomitantemente, transformações sociais, de modo que os espaços de convívio com a diferença possam se ampliar 19. Desconsiderar tal articulação incita práticas disciplinares e prescritivas, por serem desvinculadas da experiência vivida e significada pelo paciente ${ }^{3}$.

Sendo assim, vale questionar se os profissionais não estariam destinando demasiadamente seus investimentos para o cotidiano do CAPS, em detrimento da construção de um trabalho compartilhado com a atenção básica, por exemplo. Não obstante os trabalhadores relatarem a realização de apoio matricial em UBS, identificamos que a clínica dos pacientes psicóticos permanece localizada dentro do CAPS e, em certa medida, dissociada de práticas radicadas no território dos pacientes. Esse quadro é evidenciado pelos familiares que reconhecem nos técnicos de referência sua única fonte de ajuda. Observe-se que essa forma de organizar o trabalho pode favorecer o excesso de responsabilização dos profissionais de referência, tal como eles mesmos se queixam.

Notemos, entretanto, que os profissionais que participaram da pesquisa reclamam que, muitas vezes, não contam com o apoio de atores fora do CAPS. Logo, é preciso considerar também a necessidade de ações da política de saúde e de intersetorialidade que ofereçam recursos para o trabalho junto ao território.

Faz-se necessário, ainda, reconhecer a complexidade que envolve a construção de um trabalho próximo ao usuário e, simultaneamen- te, compartilhado com profissionais de dentro e fora do CAPS. Tal complexidade exige que a equipe disponha de espaços de supervisão institucional para analisar suas defesas inconscientes e tratar dos sofrimentos inerentes a uma prática que envolve relações íntimas com colegas e pacientes 20 . Relações estas que ocorrem num campo em que, sem se desfazer dos núcleos disciplinares, é necessário flexibilizar suas fronteiras, a fim de ampliar a capacidade de compreensão e intervenção sobre as necessidades globais do paciente 21 .

Os aspectos que familiares e usuários valorizam do trabalho de referência nos permitem defender que a função de mediação da vida cotidiana dos usuários é facilitada pelo arranjo, uma vez que, através deste, os profissionais devem acompanhar seus pacientes nas diversas esferas da vida. Assim, concepções de clínica que consideram o sujeito na sua constante relação com o mundo social 3 instrumentalizam o profissional de referência a realizar também um importante trabalho político, na medida em que estimulam negociações entre os usuários e a cidade, contribuindo para que os sujeitos ampliem sua capacidade de realizar trocas e dialogar com a diferença. Consequentemente, esses profissionais participam da execução da tarefa política da Reforma Psiquiátrica brasileira 19.

Observemos que, ao desempenhar a mediação do cotidiano dos usuários, não cabe ao técnico de referência fazer por estes, mas sim se adaptar ao ritmo e às necessidades deles, oferecendo suporte para o contato consigo e com o outro, bem como para as vivências que decorrem desse contato, estejam elas relacionadas ao ganho de autonomia ou a sensações de agonia e ruptura 22. No entanto, os profissionais asseveram que esse processo lhes exige o estabelecimento de relações muito próximas com seus pacientes, as quais os sensibilizam para diferentes questões, como aquelas ligadas às paixões profundas dos usuários ou à vida social destes, geralmente permeada por extrema miséria. Tamanha proximidade pode levar o técnico de referência a assumir atitudes onipotentes ou controladoras, correndo o risco de "controlar tudo direitinho", conforme aponta uma usuária. Nesse contexto, ele tende a oscilar movimentos em que fica identificado com o paciente (de modo excessivo e patológico) e outros em que tenta dele se afastar, podendo desenvolver, por exemplo, práticas burocráticas cindidas da clínica.

Essas considerações nos levam a supor que o trabalho de referência estrutura-se sobre um paradoxo: por um lado, os pacientes precisam de relações singulares, em que os profissionais se identifiquem com eles e reconheçam sua sin- 
gularidade. Por outro lado, precisam também de um arranjo sólido, que interdite tal identificação, quando ela não se mostra patológica. Portanto, é imprescindível a constante comunicação entre as estruturações coletivas e individualizadas, para que elas, permanentemente, sustentem-se, desestabilizem-se e toquem-se. Esse fluxo de movimento permite que o paciente encontre variados espaços para experimentar sua polifonia, alojá-la e movimentá-la ${ }^{23}$. Dentre as estruturas coletivas de sustentação, destacamos as equipes de referência e os serviços e atores sociais de diferentes áreas, como educação e serviço social.

Os profissionais reconhecem que as equipes de referência funcionam como espaço de compartilhamento dos casos e de trocas de saberes, mas também observam que nem sempre elas funcionam desse modo. Salientamos que a sustentação dos espaços de compartilhamento nas equipes exige regularidade de encontros, discussões e trabalho em comum, o que requer certa escolha por parte dos profissionais de construírem e sustentarem uma instância coletiva de gestão da clínica. As oficinas da pesquisa criaram parâmetros para a avaliação desse trabalho, propondo a verificação do número casos discutidos e de atores envolvidos nessa discussão. Contudo, tal como os profissionais indicam, é provável que esse acompanhamento encontre resistências situadas nas relações de mercado de trabalho, nas buscas pessoais pela diferenciação e nas angústias ligadas aos ferimentos narcísicos, inerentes ao contato com a diferença 6 . Acreditamos ser viável lidar com esses problemas através da sustentação de uma política pública de saúde mental, orientada pelos princípios da Reforma Psiquiátrica, e por meio da orientação clínica indicada pelos pacientes.

Cientes da complexidade que envolve esse trabalho, sugerimos que o profissional de referência sustente suas práticas em alguns balizamentos éticos oferecidos pelas regras técnicas freudianas 24 que interditam as pretensões onipotentes de tudo escutar, entender e saber 24 . Para tanto, indicamos que desenvolvam habilidade de suportar a habitação de uma zona paradoxal, localizada num interstício entre sua presença implicada junto ao paciente e sua capacidade de ausentar-se, colocando-se em reserva 25 . Assim, é necessário colocar-se disponível para experimentar um contato emocional vivo com o paciente, mas, ao mesmo tempo, conseguir se ausentar, reservando a este o centro da cena. Para tanto, pode contar com suas próprias reservas, como as experiências pessoais, a capacitação técnica, a supervisão 25 e também com a equipe de referência.

\section{Conclusão}

Nosso material de pesquisa indica que o arranjo "equipes de referência" é a principal instância de organização do processo de trabalho e assistência dos CAPS estudados. Sendo assim, ele desempenha uma importante função de gestão da clínica desses serviços, determinando modelos de intervenção junto ao usuário e à rede. Independentemente da forma como o arranjo é organizado, seu maior desafio permanece localizado nas possibilidades de trocas entre os agentes envolvidos com a atenção dentro e fora dos CAPS. Tais trocas são complexas porque envolvem elementos paradoxais, contidos em experiências de relação com pacientes que exigem a coexistência de planos coletivos e individuais, internos e externos, rigorosamente éticos e espontâneos.

Consideramos que as oficinas realizadas na pesquisa auxiliam no manejo desse desafio, na medida em que propõem a constante avaliação da capacidade das equipes de referência em realizar a discussão coletiva dos casos e a ampliação das ofertas de encontros dos usuários com os profissionais e outros atores de seu meio social. Transitar entre a construção coletiva do tratamento e a relação íntima e espontânea com os pacientes, no meio social destes, constitui a delicada tarefa dos profissionais de referência.

Não priorizamos, nesta pesquisa, a busca de informações acerca das especificidades das categorias profissionais no exercício de referenciar, o que nos impossibilitou de analisar as relações de poder inerentes ao trabalho de equipe. Futuros estudos podem incrementar as construções alcançadas por nosso campo e investigar tais relações, contribuindo para o manejo do desafio de criar e manter trocas interprofissionais nos CAPS e no território dos pacientes. 


\section{Resumo}

Esse trabalho utilizou uma metodologia qualitativa, avaliativa e participante, baseada na Hermenêutica Gadameriana e no paradigma construtivista. O objetivo foi analisar o arranjo denominado "equipes de referência", em relação ao tratamento de pacientes psicóticos, no contexto dos Centros de Atenção Psicossocial (CAPS). A coleta de dados foi feita em dois ciclos de 18 grupos focais, compostos por profissionais, usuários e familiares de usuários de seis CAPSIII, por oito entrevistas em profundidade, desenvolvidas com usuários desses serviços, e por duas oficinas de construção de um guia para avaliação das práticas dos CAPS. Foram indicadas as funções do arranjo, destacando que as equipes de referência se constituem como instâncias de gestão da clínica, propiciando o acompanhamento no campo das necessidades singulares do paciente, através do trabalho interdisciplinar. Para isso, devem sustentar um posicionamento ético baseado no respeito à alteridade e na construção do caso clínico.

Equipe de Assistência ao Paciente; Serviços de Saúde Mental; Gestão Clínica

\section{Referências}

1. Departamento de Ações Programáticas Estratégicas, Secretaria de Atenção à Saúde, Ministério da Saúde. Saúde mental no SUS: os centros de atenção psicossocial. Brasília: Ministério da Saúde; 2004.

2. Tenório F. Questões para uma atualização da agenda da Reforma Psiquiátrica. In: Couto MCV, Martinez RG, organizadores. Saúde mental e saúde pública: questões para a agenda da Reforma Psiquiátrica. Rio de Janeiro: Núcleo de Pesquisa em Políticas Públicas de Saúde Mental, Instituto de Psiquiatria, Universidade Federal do Rio de Janeiro; 2007. p. 11-28.

3. Leal EM, Delgado PGG. Clínica e cotidiano. O Caps como dispositivo de desinstitucionalização. In: Pinheiro R, Guljor AP, Silva Jr. AG, Mattos RA, organizadores. Desinstitucionalização da saúde mental: contribuições para estudos avaliativos. Rio de Janeiro: Centro de Estudos e Pesquisa em Saúde Coletiva, Instituto de Medicina Social, Universidade do Estado do Rio de Janeiro/ABRASCO; 2007. p. 137-54.

\section{Colaboradores}

L. Miranda participou da coleta de dados, interpretação, concepção teórica e revisão crítica do artigo. R. T. Onocko-Campos participou da interpretação, concepção teórica e revisão crítica do artigo.
4. Miranda L, Onocko-Campos RT. Análise do trabalho de referência em Centros de Atenção Psicossocial. Rev Saúde Pública 2008; 42:907-13.

5. Campos GWS, Domitti AC. Apoio matricial e equipe de referência: uma metodologia para gestão do trabalho interdisciplinar em saúde. Cad Saúde Pública 2007; 23:2399-407.

6. Furtado JP. Equipes de referência: arranjo institucional para potencializar a colaboração entre disciplinas e profissões. Interface Comunic Saúde Educ 2007; 11:239-55.

7. Departamento de Ações Programáticas Estratégicas, Secretaria de Atenção à Saúde, Ministério da Saúde. Resultados Avaliar CAPS 2008 para colegiado. Brasília: Ministério da Saúde; 2004.

8. Furtado JP, Miranda L. O “dispositivo técnico de referência" nos equipamentos substitutivos de saúde mental e o uso da psicanálise winnicottiana. Rev Latinoam Psicopatol Fundam 2006; 9:2508-25.

9. Ryan A. Case management: a critical review. Community Care 2003; 10:127-32. 
10. Machado LF, Dahl CM, Carvalho MCA, Cavalcanti MT. Programa de tratamento assertivo na comunidade (PACT) e gerenciamento de casos (case management): revisão de 20 anos de literatura. J Bras Psiquiatr 2007; 56:208-18.

11. Gadamer HG. Verdade e método: traços fundamentais de uma hermenêutica filosófica. Petrópolis: Editora Vozes; 1997.

12. Minayo MCS. O desafio do conhecimento: pesquisa qualitativa em saúde. 9a Ed. São Paulo: Editora Hucitec; 2006.

13. Denzin NK. Lincoln YS. Handbook of qualitative research. Thousand Oaks: Sage; 1994.

14. Furtado JP, Onocko-Campos R. O percurso da pesquisa avaliativa de uma rede de Centros de Atenção Psicossocial: entre a saúde coletiva e a saúde mental. In: Onocko-Campos R, Furtado JP, Passos E, Benevides R, organizadores. Pesquisa avaliativa em saúde mental: desenho participativo e efeitos de narratividade. São Paulo: Aderaldo \& Rothschild; 2008. p. 189-208.

15. Miranda L, Figueiredo MD, Ferrer AL, OnockoCampos RT. Dos grupos focais aos grupos focais narrativos: uma descoberta no caminho da pesquisa. In: Onocko-Campos R, Furtado JP, Passos E, Benevides R, organizadores. Pesquisa avaliativa em saúde mental: desenho participativo e efeitos de narratividade. São Paulo: Aderaldo \& Rothschild; 2008. p. 249-77.

16. Onocko-Campos R, Furtado JP. Narrativas: utilização na pesquisa em saúde. Rev Saúde Pública 2008; 42:1090-6.

17. Figueiredo MD, Santos DVD. A rede de saúde do município de Campinas (SP): peculiaridades e inovações. In: Onocko-Campos R, Furtado JP, Passos E, Benevides R, organizadores. Pesquisa avaliativa em saúde mental: desenho participativo e efeitos de narratividade. São Paulo: Aderaldo \& Rothschild; 2008. p. 155-62.
18. Figueiredo AC. A construção do caso clínico: uma contribuição da psicanálise à psicopatologia e à saúde mental. Rev Latinoam Psicopatol Fundam 2004; 7:175-86.

19. Honorato CEM, Pinheiro R. O "cuidador da desinstitucionalização": o trabalho político das equipes de saúde mental nos serviços residenciais terapêuticos. In: Pinheiro R, Guljor AP, Silva Jr. AG, Mattos RA, organizadores. Desinstitucionalização da saúde mental: contribuições para estudos avaliativos. Rio de Janeiro: Centro de Estudos e Pesquisa em Saúde Coletiva, Instituto de Medicina Social, Universidade do Estado do Rio de Janeiro/ABRASCO; 2007. p. 169-88.

20. Onocko-Campos, R. O encontro trabalhadorusuário na atenção à saúde. Uma contribuição da narrativa psicanalítica ao tema do sujeito na saúde coletiva. Ciênc Saúde Coletiva 2005; 10:573-83.

21. Campos GWS, Chakour M, Santos RC. Análise crítica sobre as especialidades médicas e estratégias para integrá-las ao Sistema Único de Saúde (SUS). Cad Saúde Pública 1997; 13:141-4.

22. Winnicott DW. Os doentes mentais na prática clínica. In: Winnicott DW, organizador. O ambiente e os processos de maturação. Porto Alegre: Artes Médicas; 1983. p. 196-206.

23. Oury J. Le collectif. Paris: Sacarabé; 1986.

24. Freud S. O caso Schreber, artigos sobre a técnica e outros trabalhos: 1911-1913. Rio de Janeiro: Imago; 1996. (Edição Standard Brasileira das Obras Completas de Sigmund Freud, 12).

25. Figueiredo LCM. Novas considerações sobre implicação e reserva. In: Figueiredo LCM, Coelho Jr. NE, organizadores. Ética e técnica em psicanálise. 2a Ed. São Paulo: Escuta; 2008. p. 107-22.

Recebido em 23/Out/2009

Versão final reapresentada em 29/Mar/2010

Aprovado em 19/Abr/2010 